\title{
Determinantes da satisfação e atributos da qualidade em serviços de hotelaria
}

\author{
Gabriela Musse Brancoa,*, José Luis Duarte Ribeiro ${ }^{\mathrm{b}}$, \\ Maria Auxiliadora Cannarozzo Tinoco ${ }^{\mathrm{c}}$ \\ a,* gabriela.branco@ufrgs.br, UFRGS, Brasil \\ bribeiro@producao.ufrgs.br, UFRGS, Brasil \\ 'maria@producao.ufrgs.br, UFRGS, Brasil
}

\begin{abstract}
Resumo
Este artigo apresenta a identificação de atributos de qualidade percebida e a construção de um modelo de associação entre os determinantes da satisfação de clientes para serviços de hotelaria. A pesquisa foi realizada através de um levantamento (survey) conduzido junto a 100 clientes do serviço em estudo. A principal contribuição deste trabalho é a proposição de um modelo que detalha a força do relacionamento entre os determinantes da satisfação dos clientes e a hierarquização dos atributos que exercem maior influência sobre a qualidade percebida para serviços de hotelaria. Os resultados obtidos podem ser utilizados pelos gestores de hotéis para melhorar a satisfação dos clientes, contribuindo para o crescimento da organização. 0 trabalho desenvolvido complementa estudos realizados na área de qualidade e satisfação de clientes nos serviços de hotelaria.
\end{abstract}

Palavras-chave

Satisfação de clientes. Atributos da qualidade. Serviços de hotelaria.

\section{Introdução}

A evolução da sociedade pode ser dividida em três estágios de desenvolvimento econômico: sociedade pré-industrial, sociedade industrial e sociedade pós-industrial. Atualmente, a sociedade encontra-se no último estágio, caracterizado pela economia de serviços, preocupação com a qualidade de vida e crescimento populacional. Nesse contexto, observa-se o crescimento de vários setores de serviços, como: saúde, educação, lazer, transporte público, bancário, imóveis, seguros (FITZSIMMONS, J. A.; FITZSIMMONS, M. J., 2005).

0 setor de serviços vem ocupando posição de destaque na economia mundial. Em 2003, esse setor representava 73\% do PIB (Produto Interno Bruto) no Reino Unido, sendo responsável por 75\% dos empregos totais. Já nos EUA o impacto do setor de serviços no PIB foi de 77\%, gerando mais de 76\% dos empregos totais para o mesmo ano (GRÖNROOS, 2007). Apesar de os países de terceiro mundo não acompanharem a velocidade das mudanças observadas nos países

desenvolvidos, no Brasil, percebe-se a mesma tendência referente à importância e ao crescimento no setor de serviços. Segundo dados do Instituto Brasileiro de Geografia e Estatística (IBGE), no Brasil o setor empregava aproximadamente $61 \%$ do total de ocupações e foi responsável por 56,5\% do PIB em 2006 (INSTITUTO..., 2008).

Diante desse cenário de mercados competitivos, onde o setor de serviços está ocupando uma posição importante na economia, as organizações reconhecem a necessidade de conquistar e manter clientes para garantir a sua sobrevivência (TINOCO; RIBEIR0, 2007). Para isso, as empresas devem buscar constantemente a qualidade de seus serviços e a satisfação de seus consumidores.

0 serviço de hotelaria pode ser apresentado como um exemplo representativo do setor terciário e da importância da satisfação dos clientes. Esse setor está em crescimento, acompanhando o acelerado desenvolvimento do setor de turismo. 
Segundo Vieira (2002, apud ANJOS et al., 2005), esse é um dos setores que mais avançam no mundo, e a mesma situação é observada no Brasil.

De acordo com Tinoco e Ribeiro (2007), o relacionamento entre os determinantes da satisfação dos clientes é diferente para cada tipo de serviço. Exemplificando, para alguns serviços a imagem corporativa pode ser essencial, para outros, a qualidade percebida ou o custo são os elementos essenciais. Assim, existe a necessidade de investigar os determinantes e a relação entre eles que conduzem à satisfação do cliente para cada serviço em particular.

Paralelamente, uma vez que a qualidade percebida é um dos principais determinantes que afetam a satisfação dos clientes de serviços (TINOCO, 2006), fazem-se necessários o estudo e a identificação dos critérios segundo os quais os clientes avaliam a excelência do serviço. Dessa forma, o prestador de serviço pode priorizar seus esforços para atender aqueles atributos considerados mais importantes pelos clientes.

Nesse contexto, este artigo apresenta a construção de um modelo de satisfação dos clientes para o serviço de hotelaria através do estudo da relação entre determinantes da satisfação e a investigação dos atributos que afetam a qualidade percebida dos clientes para o mesmo serviço.

0 presente artigo está organizado conforme segue. A seção 2 apresenta uma revisão da literatura referente a determinantes da satisfação do cliente e atributos da qualidade em serviços de hotelaria. A seção 3 descreve os procedimentos metodológicos utilizados no desenvolvimento da pesquisa. Os resultados obtidos são apresentados e discutidos na seção 4 e, por fim, as conclusões do trabalho são sumarizadas na seção 5 .

\section{Referencial teórico}

\subsection{Determinantes da satisfação de clientes}

Kotler e Keller (2006) definem satisfação como sendo a sensação de prazer do cliente ao comparar desempenho percebido de um produto com as suas expectativas. 0 cliente insatisfeito é aquele que percebe um desempenho inferior às expectativas, 0 satisfeito é aquele em que o desempenho do que foi comprado correspondeu às suas expectativas. Por outro lado, se o desempenho for maior do que o esperado, esse cliente ficará muito satisfeito. $\mathrm{Na}$ mesma vertente, Pizam e Ellis (1999) contextualizam satisfação do cliente como um conceito psicológico que envolve sensação de bem-estar e prazer. Esse sentimento é gerado quando o cliente obtém o que ele espera de um produto ou serviço.

Lovelock e Wright (2001) relatam que a satisfação do cliente é um ponto crítico em setores altamente competitivos, pois clientes meramente satisfeitos podem ser atraídos pelos concorrentes, enquanto clientes completamente satisfeitos apresentam maior tendência de se manterem fiéis. Várias pesquisas confirmam que a satisfação é um determinante chave das intenções futuras dos clientes (BIGNÉ; MATTILA; ANDREU, 2008; MARTIN et al., 2008; VLACHOS; VRECHOPOULOS, 2008) e que níveis altos de satisfação geram muitos benefícios para as empresas, pois resultam em maior fidelidade e, a longo prazo, é mais lucrativo manter bons clientes do que constantemente atrair novos para substituir os que saem (LOVELOCK; WRIGHT, 2001; MORGAN; REG0, 2006).

Conceitualmente, Churchill e Surprenant (1982) definem satisfação como um resultado da comparação entre os benefícios e os custos da compra, em relação às expectativas prévias. Operacionalmente, os mesmos autores relatam que satisfação é uma atitude que considera os atributos dos produtos e serviços.

A literatura apresenta vários modelos de satisfação de clientes, em que as variáveis que afetam a avaliação que o consumidor faz do produto ou serviço e - em consequência, sua satisfação - são chamadas de determinantes da satisfação. Esses determinantes podem ser muito diversos. A desconfirmação de expectativas é indicada por vários autores como determinante direto da satisfação do cliente (e.g., OLIVER, 1980, 1993; SPRENG et al., 1996; Van RYZIN, 2005; CARO; GARCíA, 2007; BIGNÉ; MATTILA; ANDREU, 2008). Outros determinantes da satisfação do cliente apontados na literatura são: a qualidade percebida (JIANG; WANG, 2006), o valor (WHITTAKER; LEDDEN; KALAFATIS, 2007; VLACHOS; VRECHOPOULOS, 2008; LAl et al., 2009), as emoções (MARTIN et al., 2008; BIGNÉ; MATTILA; ANDREU, 2008), a imagem corporativa (ANDREASSEN; LINDESTAD, 1998; LAl et al., 2009), entre outros.

Tinoco e Ribeiro (2007) propõem um modelo de satisfação de clientes para serviços de restaurantes à la carte, que pode ser observado na Figura 1. Conforme esses autores, os principais determinantes da satisfação de clientes apresentados na literatura são: desejos, expectativas, emoções, qualidade percebida, preço, valor percebido, desconfirmação de expectativas e imagem corporativa. Esses determinantes são discutidos a seguir. 


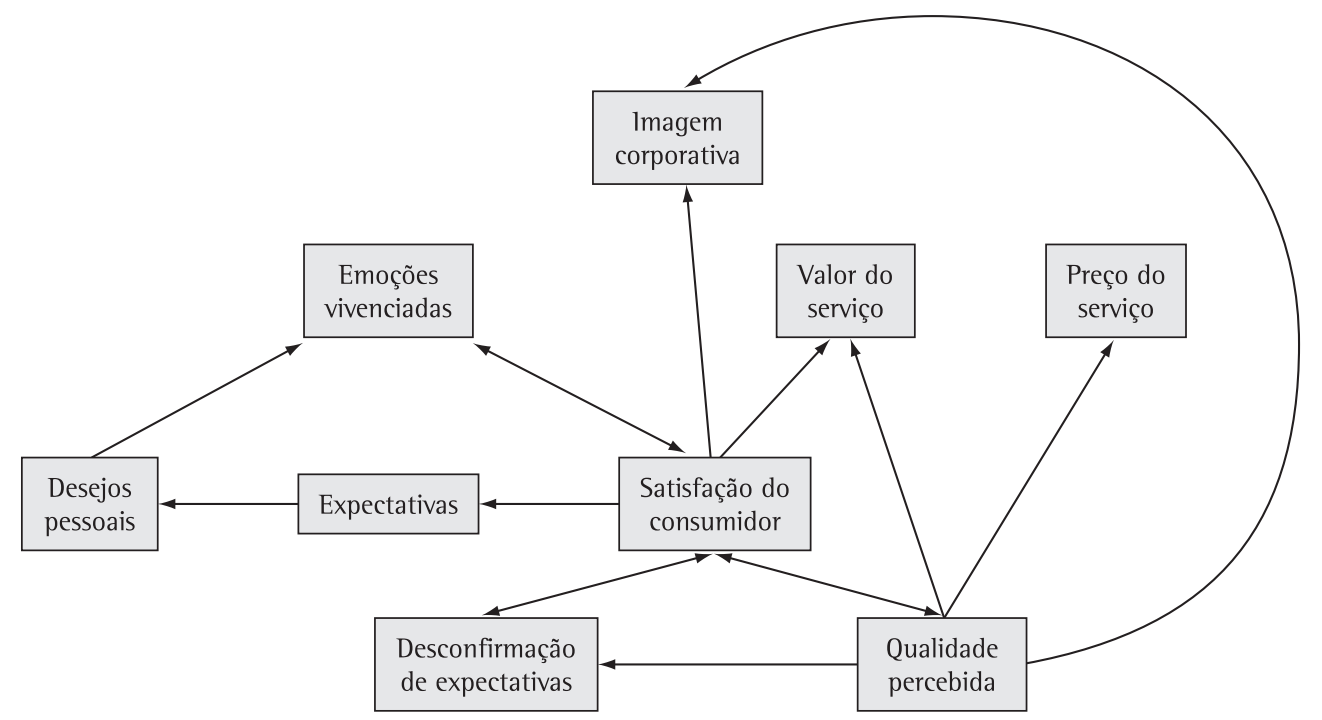

Figura 1. Modelo de associação entre determinantes da satisfação dos clientes para restaurantes à la carte. Fonte: Tinoco e Ribeiro (2007).

Um desejo é o anseio de se ter mais satisfação do que é necessário. A necessidade provém de um desconforto nas condições físicas ou psicológicas, já os desejos nascem da vontade das pessoas de elevar essas condições a um nível além do estado de conforto mínimo (SHETH; MITTAL; NEWMAN, 2001).

Conforme Oliver (1980), as expectativas dos clientes podem ser consideradas um quadro de referência sobre oqual osclientescomparam o produto ou serviço adquirido. Na mesma vertente, Churchill e Surprenant (1982) afirmam que as expectativas refletem o desempenho antecipado do produto ou serviço. Essas expectativas são influenciadas por necessidades pessoais, comunicação boca-aboca, experiência anterior e comunicações externas (PARASURAMAN; ZEITHAML; BERRY, 1985; GIANESI E CORRÊA, 2006). Kotler e Keller (2006) selecionaram fatores de influência semelhantes na formação das expectativas: experiência de compras anteriores, conselhos de conhecidos e informações da prestadora do serviço e concorrentes.

Para Sheth, Mittal e Newman (2001, p. 338),

As emoções são a consciência da ocorrência de alguma excitação fisiológica seguida por uma resposta comportamental, juntamente com a avaliação do significado de ambas.

Esses autores também afirmam que expectativas ou objetivos não atingidos geram sentimentos negativos (emoções negativas) que tendem a afastar as pessoas. No caso dos clientes, eles evitarão recomprar do fornecedor do serviço ou produto. Se os objetivos forem atingidos, as emoções serão positivas, gerando motivações de aproximação e repetição de compra.

Tinoco (2006) relata que diversos autores definem qualidade percebida como a avaliação do cliente sobre a excelência do produto ou serviço. Johnson, Nader e Fornell (1996) indicam que qualidade percebida pode ser considerada como desempenho percebido, definindo-o como a percepção do serviço pelos clientes relacionando os benefícios recebidos com os esforços desprendidos para se obter o serviço. Conforme Churchill e Surprenant (1982), o crescimento positivo do desempenho percebido aumenta a satisfação do cliente. Para Gianesi e Corrêa (2006), a percepção da qualidade é formada em cada momento em que o cliente está em contato com a empresa fornecedora do serviço. Esses autores também afirmam que a qualidade percebida sofre influência tanto da prestação do serviço em si como da comunicação transmitida ao cliente.

Preço do serviço é o montante que se paga para a obtenção do mesmo. Kotler e Keller (2006) afirmam que, embora outros fatores sejam importantes, o preço é, tradicionalmente, o principal determinante na decisão de compra, em especial para grupos mais pobres e para produtos classificados como commodities. Esses autores também colocam o preço como elemento-chave para as empresas na determinação da participação de mercado e da lucratividade. Os clientes interpretam um preço baseando-se nos conhecimentos adquiridos em compras anteriores, nas comunicações formais e informais, nos pontos de venda e nos recursos on-line. A partir disso, os consumidores estabelecem 
um limite mínimo e um máximo que será aceito como preço do serviço procurado (KOTLER; KELLER; 2006).

Os clientes não compram produtos ou serviços, eles buscam satisfazer suas necessidades e desejos. 0 valor percebido pelo cliente é a avaliação dos benefícios agregados pelos serviços ou produtos adquiridos em relação a essas necessidades e desejos. Assim, as empresas estão constantemente buscando aumentar o valor de seus serviços e produtos, aprimorando seus benefícios ou diminuindo seus custos (SHETH; MITTAL; NEWMAN, 2001). Para Choi et al. (2004), valor percebido é uma construção cognitiva que requer um trade-off entre benefícios e sacrifícios. Esses autores afirmam que o valor percebido influencia a satisfação do cliente e as suas intenções comportamentais.

Churchill e Surprenant (1982) indicam que a desconfirmação de expectativas deriva das discrepâncias entre as expectativas prévias e o desempenho real do serviço, ocupando uma posição importante nas pesquisas sobre satisfação de clientes. Oliver (1980) relata que a desconfirmação pode ser positiva, negativa ou nula, dependendo do grau em que o produto ou serviço ultrapassa as expectativas. Se a desconfirmação for positiva, tem-se satisfação; se for nula, quando as expectativas são iguais ao desempenho, tem-se uma confirmação, isto é, indiferença; e quando a desconfirmação for negativa, apresenta-se insatisfação.

A imagem corporativa é a percepção pública da organização como um todo. A conduta ética de uma corporação pode impactar nas percepções e nas decisões dos clientes sobre a mesma, pois a imagem da empresa não se relaciona somente com o produto ou serviço que ela oferece, mas também com as ações que ela toma (SHETH; MITTAL; NEWMAN, 2001). Kotler e Keller (2006) afirmam que, quanto mais forte for a imagem corporativa, mais chances a empresa tem de enfrentar as crises, especialmente as relacionadas com credibilidade e confiança na organização.

\subsection{Atributos da qualidade percebida em serviços de hotelaria}

No contexto do cenário hoteleiro do Brasil, os primeiros estabelecimentos no modelo tradicional europeu datam de 1870. Esses hotéis, sediados na capital paulista, marcaram as bases para o crescimento dos serviços de hotelaria no país. No início dos anos 20, as cidades do Rio de Janeiro e de São Paulo sofreram um forte investimento na construção de hotéis. Já na década de 40, houve uma explosão de construções de grandes estabelecimentos em todo o país. Com a criação da Embratur, os anos 70 foram marcados pelo crescimento das redes hoteleiras nacionais devido à maior disponibilidade de financiamentos de longo prazo e incentivos ficais. Na década de 80 houve uma retração dos hotéis de luxo e um crescimento dos pequenos e médios investidores, além do surgimento dos apart-hotéis. 0 início dos anos 90 sofreu uma desestabilização do setor hoteleiro em função do crescimento descontrolado da década anterior. Já no final dos anos 90, houve grande investimento da hotelaria estrangeira (ASSOCIAÇÃO..., 2008).

Segundo a ABIH (ASSOCIAÇÃO..., 2008), o setor hoteleiro brasileiro possui, atualmente, $25 \mathrm{mil}$ meios de hospedagem, sendo que 18 mil são hotéis e pousadas e 70\% são de pequeno porte. Essa associação também estima que o setor tenha um faturamento de cerca de U\$ 2 bilhões ao ano e movimente aproximadamente U\$ 8 bilhões por ano.

Cadotte e Turgeon (1988) realizaram um estudo sobre os atributos da qualidade nos serviços de hotelaria através dos registros de reclamações e elogios feitos pelos hóspedes. Esses autores afirmam que gerentes usualmente utilizam-se desse feedback para identificar pontos fracos a corrigir e pontos fortes a promover. Após analisar os dados, os autores concluíram que as reclamações apontam atributos com potencial de causar insatisfação, ao passo que os elogios indicam atributos causadores de satisfação. Para os serviços de hotelaria foi construído um ranking comparativo entre as reclamações e os elogios, conforme apresentado na Tabela 1, a partir do qual esses autores identificaram quatro tipos de atributos: de insatisfação, de satisfação, críticos e neutros.

Atributos de insatisfação são aqueles que os clientes consideram como requisito básico do serviço, ou seja, um bom desempenho nesses atributos não é capaz de melhorar a avaliação da organização pelo cliente, porém um desempenho fraco irá gerar insatisfação nos consumidores. Atributos de satisfação são aqueles que recebem mais elogios do que reclamações, isto é, são capazes de surpreender o cliente, pois não são esperados. Já os atributos críticos são aqueles fatores-chave de operação de um hotel: limpeza, qualidade do serviço, conhecimento e serviço dos funcionários e tranquilidade das redondezas. Os atributos neutros são definidos por Cadotte e Turgeon (1988) como fatores que não são capazes de receber nem reclamações nem elogios.

Farias e Santos (1998) fizeram um estudo com vinte hóspedes de três diferentes hotéis, com o intuito de descobrir os principais atributos da qualidade em serviços de hotelaria para o público da terceira idade. Esse estudo consistiu em entrevistas individuais, em que os autores identificaram nove atributos relevantes 
Tabela 1. Ranking comparativo dos atributos do serviço de hotelaria.

\begin{tabular}{|c|c|c|}
\hline Atributo & $\begin{array}{l}\text { Ranking de } \\
\text { reclamações }\end{array}$ & $\begin{array}{l}\text { Ranking } \\
\text { de elogios }\end{array}$ \\
\hline $\begin{array}{l}\text { Preço dos quartos, refeições } \\
\text { e outros serviços }\end{array}$ & 1 & 15 \\
\hline Rapidez do serviço & 2 & 11 \\
\hline Disponibilidade de estacionamento & 4 & 17 \\
\hline $\begin{array}{l}\text { Disponibilidade das acomodações } \\
\text { solicitadas }\end{array}$ & 7 & 18 \\
\hline Tempo de check-out & 8 & 23 \\
\hline Adequação das formas de pagamento & 10 & 21 \\
\hline Precisão da conta & 11 & 25 \\
\hline Atitude solícita dos funcionários & 12 & 1 \\
\hline Conforto do estabelecimento & 15 & 3 \\
\hline Conveniência da localização & 23 & 6 \\
\hline Conhecimento e serviço do gerente & 21 & 7 \\
\hline Quantidade do serviço & 13 & 8 \\
\hline Espaço do estabelecimento & 20 & 9 \\
\hline Limpeza do estabelecimento & 9 & 2 \\
\hline Qualidade do serviço & 3 & 4 \\
\hline $\begin{array}{l}\text { Conhecimento e serviço } \\
\text { dos funcionários }\end{array}$ & 5 & 5 \\
\hline Tranquilidade das redondezas & 6 & 10 \\
\hline Resposta às reclamações & 16 & 12 \\
\hline Variedade do serviço & 17 & 13 \\
\hline $\begin{array}{l}\text { Uniformidade da aparência } \\
\text { do estabelecimento }\end{array}$ & 25 & 14 \\
\hline Aparência dos funcionários & 22 & 16 \\
\hline Horas de operação & 19 & 19 \\
\hline Qualidade da publicidade & 24 & 20 \\
\hline Overbooking & 18 & 22 \\
\hline $\begin{array}{c}\text { Congestionamento do tráfego } \\
\text { no estabelecimento }\end{array}$ & 14 & 24 \\
\hline
\end{tabular}

Fonte: adaptado de Cadotte e Turgeon (1988).

e suas frequências com máximo de 40: atendimento do hotel (16); agradabilidade do hotel (13); limpeza (12); conforto do quarto (7); segurança do hotel (6); preço da diária (6); infraestrutura (5); localização (5); e serviço de copa (4).

González, Ramos e Amorim (2005) realizaram uma pesquisa com 381 hóspedes da cidade de Natal (RN) para identificar os principais atributos da qualidade em serviços de hotelaria. Concluíram que são: qualidade do quarto do hotel, cordialidade do pessoal, qualidade do restaurante relativo à comida e preço pago comparado com a qualidade recebida. Esses quatro fatores representam 56\% da satisfação do cliente com o hotel.

Chan e Wong (2006) fizeram um levantamento sobre os atributos que influenciam os clientes a fazer uma reserva em um hotel. Para a realização da pesquisa, os autores utilizaram um questionário e entrevistaram 570 viajantes no aeroporto internacional de Hong Kong. Os resultados apontam que localização conveniente e serviço de qualidade são os principais atributos que influenciam as escolhas dos consumidores. Além disso, os autores fizeram um estudo acerca de outros atributos citados por diferentes autores, destacando-se: segurança, conduta dos funcionários, ambiente silencioso, serviços pessoais e limpeza.

Em um estudo sobre os atributos que influenciam a qualidade percebida em serviços de hotelaria, Akan (1995) realizou um levantamento de dados através de um questionário aplicado a 228 pessoas no aeroporto de lstambul, Turquia. Neste questionário foram expostos 30 atributos divididos em três grupos: hotel, pessoal (funcionários) e processos do serviço. Entre os resultados encontrados destacam-se: cortesia, competência e aparência física dos funcionários; velocidade das transações; aparência interior e exterior; facilidade de acesso; produtos oferecidos para uso; exatidão das reservas; soluções a problemas.

A partir dos trabalhos apresentados, pode-se observar que o atendimento pelos funcionários e a localização aparecem como atributos relevantes em todos os trabalhos. A limpeza do quarto mostrou-se importante nos estudos de Cadotte e Turgeon (1988), Farias e Santos (1998) e Chan e Wong (2006).

\section{Procedimentos metodológicos}

Uma das técnicas mais utilizadas para a modelagem da satisfação de clientes é a análise de equações estruturais, também conhecida como SEM (Structural Equations Modeling). Essa técnica provê um método para lidar com múltiplos relacionamentos simultaneamente, apoiado em procedimentos estatísticos. Porém, antes do uso da modelagem de equações estruturais, é preciso atender alguns aspectos, como: (i) a necessidade de um modelo teórico ou conceitual que especifique as relações entre um conjunto de variáveis, podendo incorrer em erro de especificação; (ii) a necessidade de amostras relativamente grandes, que crescem rápido à medida que os modelos se tornam complexos; e (iii) necessidade de uma base de dados quantitativa. No caso em estudo, as variáveis envolvidas (tais como desejos, emoções, expectativas, qualidade percebida, preço percebido e satisfação) são essencialmente subjetivas e de difícil quantificação (GOSLING; GONÇALVES, 2003; HAIR et al., 1998).

Tinoco e Ribeiro (2007) propõem uma abordagem para modelar as relações entre determinantes da satisfação de clientes de serviços que contorna as limitações anteriormente descritas. Essa abordagem caracteriza-se por (i) empregar procedimentos mais simples do que a técnica de equações estruturais; 
(ii) requerer amostras relativamente pequenas; e (iii) permitir maior abrangência de investigação, pois pode contemplar um número maior de determinantes da satisfação de clientes sem inviabilizar o estudo (TINOCO; RIBEIRO, 2007). Sendo assim, neste trabalho foi utilizada a abordagem proposta por Tinoco e Ribeiro (2007) para a identificação das relações entre os determinantes da satisfação de clientes de serviço de hotelaria e construção do modelo de satisfação de clientes.

Os procedimentos levados a cabo para a construção do modelo de associação entre os determinantes da satisfação de clientes e para a identificação dos atributos de qualidade percebida para o serviço em estudo foram conduzidos em duas fases, que são:

\subsection{Fase 1: Identificação das relações existentes entre os determinantes do modelo de satisfação do consumidor}

Nesta fase objetivou-se identificar as relações existentes entre os determinantes da satisfação do cliente e construir o modelo de satisfação para os serviços de hotelaria. Para tanto, foi seguida a abordagem proposta por Tinoco e Ribeiro (2007), que contempla três etapas: (i) definição dos determinantes; (ii) aplicação da pesquisa; e (iii) construção do modelo.

A primeira etapa não está no escopo do estudo, pois, para facilitar comparações entre modelos obtidos em diferentes tipos de serviços, foram utilizados os mesmos determinantes sugeridos pelos autores: imagem corporativa, desejos pessoais, expectativas, emoções vivenciadas no momento, qualidade percebida, preço do serviço, valor do serviço, desconfirmação de expectativas, satisfação gerada pelo serviço.

A segunda etapa consiste da aplicação de uma pesquisa descritiva para identificar as relações entre os determinantes da satisfação do cliente. Essa pesquisa é feita através de um questionário contendo nove perguntas que indagam sobre a dependência de cada um dos determinantes em relação aos outros. A pesquisa foi realizada no estado do Rio Grande do Sul e abordou indivíduos que tinham o ensino médio concluído e utilizavam serviços de hotelaria no mínimo uma vez a cada seis meses, não importando se a turismo ou trabalho. Atendidos esses requisitos, os indivíduos foram selecionados aleatoriamente, de forma a estabelecer uma amostra diversificada no que tange a sexo, idade e classe social. Esses critérios foram definidos devido à complexidade da terminologia usada na pesquisa e à necessidade dessa população ser familiarizada e frequentadora de serviços hoteleiros. Também foi definido que, para esta pesquisa, seriam coletados dados de 50 pessoas. Esse tamanho de amostra mostrou-se suficiente nas pesquisas realizadas por Tinoco e Ribeiro (2007), e sua adequação foi confirmada neste trabalho, uma vez que permitiu identificar uma série de relações significativas entre os determinantes (uma amostra muito pequena não revelaria relações estatisticamente significativas).

Quanto ao instrumento de coleta, foi utilizado o questionário proposto por Tinoco e Ribeiro (2007), acompanhado por uma folha explicativa dos conceitos dos determinantes (tanto o questionário como os conceitos estão apresentados nos Anexos 1 e 2). Ao entrevistado foi solicitado que marcasse uma ou mais variáveis das quais o determinante em questão depende. A coleta dos dados foi realizada através de entrevistas individuais, em que os conceitos eram explicados ao entrevistado. 0 preenchimento só era iniciado após o entrevistado manifestar entendimento dos termos envolvidos. Além disso, o entrevistado podia sanar dúvidas junto ao entrevistador em qualquer momento ao longo do preenchimento.

$\mathrm{Na}$ terceira etapa foi elaborada uma matriz contendo as contagens das respostas obtidas na pesquisa. Utilizando essas contagens, realizou-se o cálculo dos resíduos padronizados, que permitem determinar as relações estatisticamente significativas entre os determinantes. Para tanto, foi utilizada a Equação 1 (AGRESTI; FINLEY, 1997 apud TINOCO; RIBEIRO, 2007):

$r_{i j}=\frac{f_{o}-f_{e}}{\sqrt{f_{e}(1-\% \text { da linha })(1-\% \text { da coluna })}}$

onde:

- $r_{i j}$ : resíduo padronizado;

- $f_{0}$ : valor observado (contagem obtida para cada determinante); e

- $f_{e}$ : valor esperado (média dos valores observados).

Utilizou-se como critério para considerar relações significativas entre os determinantes valores de resíduos padronizados maiores que $+1,96$, as quais indicam relações estatisticamente significativas considerando um nível de confiança de 0,05 (nível usualmente adotado nos estudos de Engenharia e Ciências Sociais).

ldentificadas as relações significativas entre os determinantes, foi construído o diagrama de associação, que representa o modelo de satisfação obtido para o serviço em estudo. No desenho do diagrama de associação, as setas representam o sentido da influência de um determinante sobre outro (TINOCO; RIBEIRO, 2007). 


\subsection{Fase 2. Identificação e hierarquização dos atributos que afetam a qualidade percebida pelo cliente}

Nesta fase foi feita, primeiramente, a identificação dos atributos que influenciam a qualidade percebida pelos clientes de serviços de hotelaria, a serem incluídos na pesquisa de hierarquização. A seleção dos atributos a serem avaliados foi realizada através de pesquisas na literatura e levantamento com usuários desse tipo de serviço. Assim, a partir das pesquisas relatadas na seção anterior, foi elaborada a Tabela 2 contendo os principais atributos que afetam a qualidade percebida pelos clientes de serviços de hotelaria.

Uma vez identificados os atributos de qualidade para o serviço em estudo, elaborou-se o instrumento de pesquisa para a hierarquização dos atributos de qualidade. Para tanto, os atributos selecionados foram divididos em grupos, conforme suas características e afinidades, com o intuito de facilitar o trabalho dos respondentes. Ao entrevistado foi solicitado que ordenasse, por importância, os atributos em cada grupo. Também foi solicitado que o mesmo ordenasse a importância dos grupos; com isso, foi possível hierarquizar os atributos dentro de cada grupo, como também hierarquizar os grupos. 0 questionário está apresentado no Apêndice 1.

Nesta etapa, foi definido que a população a ser estudada teria as mesmas características da população da pesquisa sobre os determinantes, contemplando outra amostra de 50 respondentes (clientes de hotéis com as mesmas características da amostra anterior). Na coleta de dados para a pesquisa sobre os atributos da qualidade, seguiram-se os mesmos procedimentos da pesquisa sobre os determinantes: seleção dos entrevistados e entrevista com entrega dos questionários. Após a coleta, os dados foram tabulados em uma planilha eletrônica para serem analisados.
A análise dos dados abrange a construção da tabela de hierarquização dos atributos que influenciam a qualidade percebida pelos clientes do serviço de hotelaria, após tratamento estatístico dos dados coletados.

\section{Estudo aplicado}

\subsection{Resultados referentes aos determinantes de satisfação}

A pesquisa sobre as relações de dependência entre os determinantes da satisfação para clientes de serviços de hotelaria foi realizada através de entrevistas individuais conforme descrito na seção anterior. Os resultados foram compilados em uma matriz que é apresentada na Tabela 3.

Analisando os resultados da primeira linha, pode-se observar que 11 respondentes indicaram que a imagem corporativa do hotel depende dos desejos pessoais; 15 responderam que a imagem depende das expectativas; 13 apontaram que as emoções vivenciadas no momento da prestação do serviço influenciam a imagem; a dependência da imagem da qualidade percebida foi apontada por 34 respondentes; 19 e 14 respectivamente responderam que a imagem corporativa depende do preço e do valor do serviço; já 40 entrevistados apontaram que a imagem depende da satisfação. Essa mesma leitura pode ser feita para as demais linhas da matriz.

A partir das contagens apresentadas na Tabela 3, foram calculados os resíduos padronizados através da Equação 1. Esses valores estão apresentados na Tabela 4, onde foram identificados os resíduos padronizados maiores do que $+1,96$ que configuram relações estaticamente significativas entre os determinantes.

Os resíduos em destaque na Tabela 4 indicam as relações causais significativas. Após a identificação

Tabela 2. Atributos considerados para a pesquisa. Fonte: elaborada pelos autores a partir de dados de Cadotte e Turgeon (1988), Farias e Santos (1998), González, Ramos e Amorim (2005), Chan e Wong (2006), Akan (1995).

\begin{tabular}{|c|c|c|}
\hline \multicolumn{3}{|c|}{ Atributos da qualidade para os serviços de hotelaria } \\
\hline Qualidade do restaurante & Disponibilidade da lavanderia & Formas de pagamento \\
\hline Disponibilidade de estacionamento & Disponibilidade das acomodações reservadas & Aparência dos funcionários \\
\hline Limpeza do quarto & Qualidade do café da manhã & Ambiente externo do hotel \\
\hline Conforto do quarto & Exatidão das reservas & Espaço do quarto \\
\hline Segurança do hotel & Ambiente interno do hotel & Resposta às reclamações \\
\hline Infraestrutura do hotel & Tempo de check-in / check-out & Atendimento \\
\hline Serviço de copa & Localização do hotel & Limpeza do hotel \\
\hline Cordialidade dos funcionários & Espaço do hall & Produtos oferecidos \\
\hline
\end{tabular}

Fonte: elaborada pelos autores. 
das relações significativas existentes entre os determinantes, foi elaborado o diagrama de associação, que caracteriza o modelo de satisfação para serviços de hotelaria. Para a construção do modelo, a força das relações entre os determinantes foi considerada forte para resíduos maiores que $+4,00$, média para resíduos entre $+3,00$ e $+4,00$ e fraca para resíduos menores que $+3,00$. 0 modelo é apresentado na Figura 2.

Tabela 3. Contagem das respostas dos questionários referentes aos determinantes.

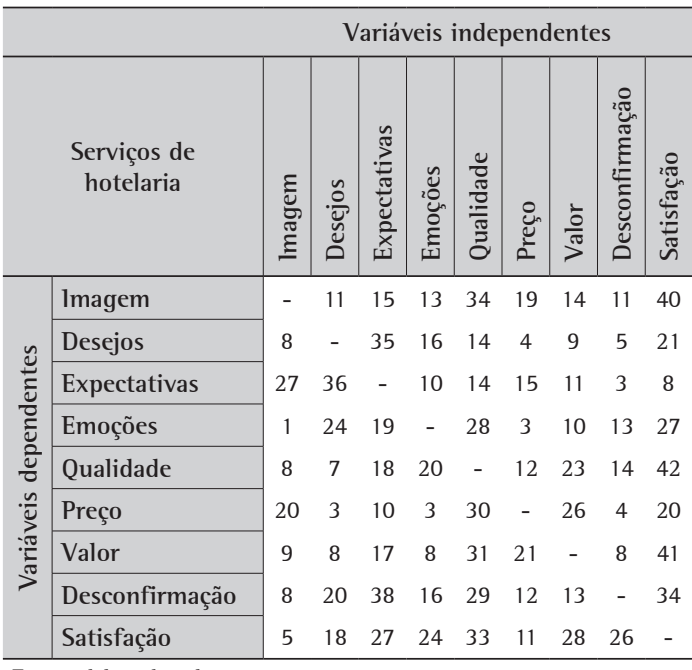

Fonte: elaborada pelos autores.
0 modelo obtido indica a existência de uma relação entre qualidade percebida, desconfirmação de expectativas e satisfação do consumidor. Esses determinantes formam um enlace triangular que é a base do modelo de satisfação. Observa-se que a qualidade percebida juntamente com a confirmação das expectativas geram satisfação do consumidor que, por sua vez, também alimenta a qualidade percebida e a desconfirmação das expectativas. Assim, um aumento na qualidade percebida, por exemplo, gera maior confirmação das expectativas e aumenta a satisfação do consumidor. Percebeu-se que esse triângulo também é a base do modelo de satisfação de clientes de restaurantes à la carte, pesquisado por Tinoco e Ribeiro (2007), apresentado na Figura 1.

Analisando-se o modelo de satisfação da Figura 2, percebe-se a existência de outro enlace: imagem corporativa, expectativas, desconfirmação das expectativas e satisfação do consumidor. A imagem da organização gera expectativas no consumidor que, ao serem confirmadas na prestação do serviço, causa satisfação. Essa satisfação, por sua vez, realimenta a imagem corporativa. Esse enlace também sofre influência da qualidade percebida, pois esse determinante interfere na satisfação e na imagem corporativa, influenciando todo o bloco enlaçado.

Tabela 4. Resíduos padronizados.

\begin{tabular}{|c|c|c|c|c|c|c|c|c|c|c|}
\hline & & \multicolumn{9}{|c|}{ Variáveis independentes } \\
\hline & Serviços de hotelaria & 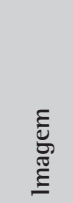 & $\begin{array}{l}\tilde{\Xi} \\
\tilde{\Xi} \\
\tilde{\Xi}\end{array}$ & 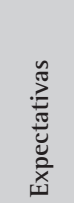 & 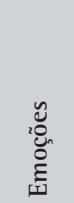 & $\begin{array}{l}\frac{2}{0} \\
\frac{\pi}{0} \\
\frac{\pi}{\pi} \\
\frac{\pi}{2}\end{array}$ & 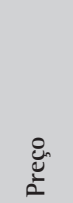 & $\frac{\frac{b}{\pi}}{>}$ & 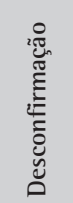 & 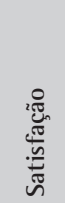 \\
\hline \multirow{9}{*}{ 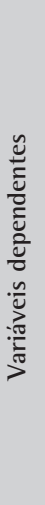 } & Imagem & - & $-1,76$ & $-0,70$ & $-1,21$ & 4,61 & 0,39 & $-0,96$ & $-1,73$ & 6,35 \\
\hline & Desejos & $-2,47$ & - & 4,71 & $-0,40$ & $-0,97$ & $-3,52$ & $-2,26$ & $-3,25$ & 0,96 \\
\hline & Expectativas & 2,46 & 4,89 & - & $-1,98$ & $-0,98$ & $-0,67$ & $-1,74$ & $-3,78$ & $-2,66$ \\
\hline & Emoções & $-4,31$ & 1,71 & 0,40 & - & 2,89 & $-3,81$ & $-2,01$ & $-1,18$ & 2,63 \\
\hline & Qualidade & $-2,51$ & $-2,82$ & 0,13 & 0,65 & - & $-1,46$ & 1,46 & $-0,93$ & 6,87 \\
\hline & Preço & 0,64 & $-3,84$ & $-2,04$ & $-3,81$ & 3,42 & - & 2,24 & $-3,51$ & 0,68 \\
\hline & Valor & $-2,24$ & $-2,55$ & $-0,15$ & $-2,53$ & 3,74 & 0,91 & - & $-2,50$ & 6,59 \\
\hline & Desconfirmação & $-2,54$ & 0,67 & 5,67 & $-0,41$ & 3,23 & $-1,48$ & $-1,23$ & - & 4,68 \\
\hline & Satisfação & $-3,34$ & 0,12 & 2,62 & 1,74 & 4,36 & $-1,75$ & 2,84 & 2,25 & - \\
\hline
\end{tabular}

Fonte: elaborada pelos autores. 


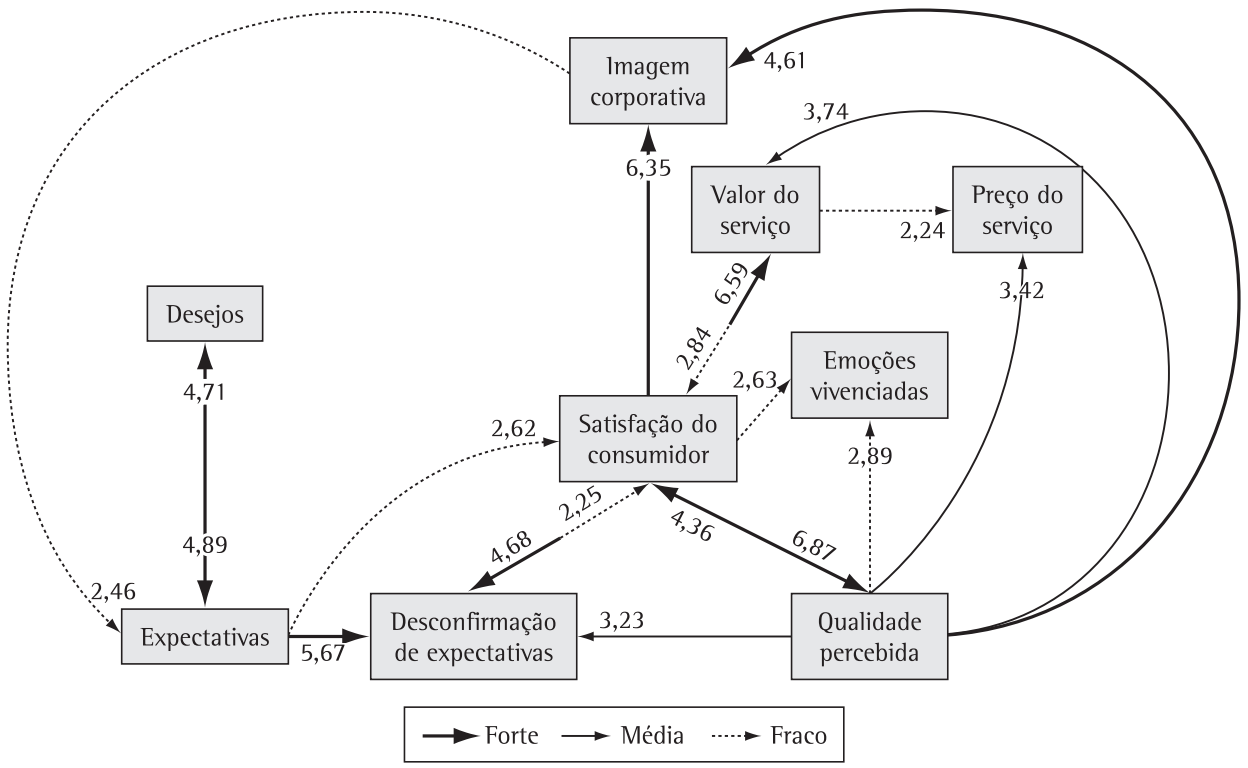

Figura 2. Modelo de associação entre os determinantes da satisfação para serviços de hotelaria.

Também pode-se perceber que as emoções vivenciadas no momento da prestação do serviço dependem da satisfação do consumidor e da qualidade percebida por ele. Além disso, nota-se que as expectativas dos clientes são formadas pelos seus desejos e pela imagem do hotel. Já a apreciação de preço depende do valor percebido (relação custo / benefício) e da qualidade percebida pelo cliente, sendo que ambos são influenciados pela satisfação do consumidor.

\subsection{Resultados referentes aos atributos da qualidade}

A pesquisa sobre a importância dos atributos que afetam a qualidade percebida foi realizada através de entrevistas individuais conforme descrito na seção anterior, onde os entrevistados responderam ao questionário do Apêndice 1, hierarquizando os atributos dentro de grupos (aspectos gerais externos, aspectos gerais internos, atendimento, infraestrutura, quarto e serviços de alimentação), bem como hierarquizando a importância dos grupos.

Após a realização da pesquisa, os dados foram tabulados em uma planilha eletrônica, onde foram tratados estatisticamente. No que se refere à hierarquização dos grupos, foi feita a soma dos inversos das posições indicadas em cada questionário (onde posição refere-se à classificação da importância do item avaliado: primeiro, segundo, terceiro, ou, numericamente, 1, 2, 3). Essa soma foi dividida pela soma dos valores dos grupos e multiplicada por 100, obtendo-se um indicativo da contribuição percentual de cada grupo para a qualidade percebida. Esses resultados são apresentados na Tabela 5.

0 segundo passo envolveu o processamento dos atributos dentro de cada grupo. Para tanto, foi feita a soma do inverso das posições indicadas nos questionários, bem como a soma total dos atributos do grupo. A soma do atributo foi dividida pela soma do grupo, e o resultado multiplicado pelo valor do grupo (obtido em sua hierarquização). Assim, tem-se um indicativo da contribuição de cada atributo para a qualidade percebida, considerando-se a importância do grupo a qual ele pertence. A Tabela 6 apresenta a classificação final dos atributos dentro de cada grupo.

Para melhor analisar os resultados obtidos para os atributos, estes foram organizados em um gráfico de Pareto. Assim, foi feita uma lista onde os atributos aparecem ordenados de forma decrescente, obtendo-se a soma acumulada dos valores. Os primeiros 15 representam $75,4 \%$ da qualidade percebida e podem ser considerados os mais importantes. Esses atributos são apresentados na Tabela 7.

Analisando-se a Tabela 5, pode-se perceber que quarto e atendimento são os aspectos mais importantes para os clientes de hotéis. Já a Tabela 7 mostra quais atributos apresentam maior contribuição para a qualidade percebida. Assim, nota-se que limpeza e conforto do quarto, exatidão das acomodações reservadas, aparência interna e limpeza do hotel são os atributos mais importantes 
Tabela 5. Resultado dos grupos de atributos da qualidade.

\begin{tabular}{cc}
\hline Grupo & $\begin{array}{c}\text { Contribuição para a } \\
\text { qualidade percebida (\%) }\end{array}$ \\
\hline Quarto & 27,4 \\
Atendimento & 20,4 \\
Infraestrutura & 16,2 \\
Aspectos gerais internos & 13,7 \\
Serviços de alimentação & 11,4 \\
Aspectos gerais externos & 10,8 \\
\hline
\end{tabular}

Fonte: elaborada pelos autores.

para os clientes de hotéis, contribuindo com 33,33\% da qualidade percebida pelo hóspede. Vale observar que a hierarquização dos grupos confirmou a importância dos atributos na qualidade percebida, pois os principais atributos de qualidade pertencem aos grupos de maior hierarquia ou de maior importância para a qualidade percebida (quarto e atendimento).

Os resultados apresentam-se semelhantes aos obtidos por Farias e Santos (1998) e González, Ramos e Amorim (2005). Os atributos mais importantes encontrados pelos primeiros autores (atendimento, agradabilidade, limpeza e conforto do quarto) também foram apontados entre os mais importantes na pesquisa realizada neste trabalho: atendimento foi o segundo grupo mais importante; agradabilidade pode ser considerada aparência interna, tendo ficado em quarto lugar; já limpeza e conforto foram os dois atributos de maior importância. Para González, Ramos e Amorim (2005), o quarto e a cordialidade (atendimento) foram os principais atributos da qualidade em serviços de hotelaria, assemelhando-se ao encontrado na classificação dos grupos. Entre os trabalhos estudados (Tabela 2), observou-se que 0 atendimento pelos funcionários e a localização apareceram como atributos relevantes em todos os trabalhos; validando, assim, a importância desses atributos, pois, na pesquisa realizada neste trabalho, a conduta dos funcionários ficou em sexto lugar e a localização do hotel em décimo. Ou seja, esses atributos são considerados importantes por todos os tipos de clientes em diversos locais do mundo. A limpeza do quarto mostrou-se importante nos estudos de Cadotte e Turgeon (1988), Farias e Santos (1998) e Chan e Wong (2006), contribuindo para a validação do resultado encontrado na presente pesquisa, onde esse atributo foi considerado o mais importante pelos entrevistados.

Não foram encontradas divergências significativas ao comparar os resultados obtidos neste trabalho com as demais pesquisas reportadas na literatura referentes a atributos de qualidade em serviços de hotel. Contudo, vale destacar algumas discrepâncias surgidas. A pesquisa de González,
Tabela 6. Resultado dos atributos por grupo.

\begin{tabular}{|c|c|c|c|}
\hline \multicolumn{2}{|l|}{ Aspectos gerais externos } & \multicolumn{2}{|l|}{ Quarto } \\
\hline Localização do hotel & 4,1 & Limpeza do quarto & 9,2 \\
\hline Acesso & 2,0 & Conforto do quarto & 7,0 \\
\hline $\begin{array}{l}\text { Aparência externa } \\
\text { do hotel }\end{array}$ & 1,9 & $\begin{array}{l}\text { Disponibilidade de } \\
\text { facilidades (TV, TV a cabo, } \\
\text { rede wireless, rádio) }\end{array}$ & 4,5 \\
\hline $\begin{array}{l}\text { Ambiente externo } \\
\text { do hotel }\end{array}$ & 1,4 & Ambiente silencioso & 3,8 \\
\hline $\begin{array}{l}\text { Disponibilidade de } \\
\text { estacionamento }\end{array}$ & 1,4 & Espaço do quarto & 2,9 \\
\hline Aspectos gerais intern & & Infraestrutura & \\
\hline Limpeza do hotel & 5,6 & Aparência interna & 5,6 \\
\hline Segurança do hotel & 3,9 & $\begin{array}{c}\text { Disponibilidade } \\
\text { de áreas de lazer } \\
\text { (piscina, churrasqueira...) }\end{array}$ & 4,4 \\
\hline Formas de pagamento & 2,5 & $\begin{array}{c}\text { Disponibilidade de } \\
\text { facilidades esportivas } \\
\text { (academia, quadra de tênis...) }\end{array}$ & 3,6 \\
\hline $\begin{array}{l}\text { Disponibilidade de } \\
\text { lavanderia }\end{array}$ & 1,7 & Espaço do hall & 2,6 \\
\hline Atendimento & & Serviços de alimentação & \\
\hline $\begin{array}{c}\text { Exatidão das } \\
\text { acomodações reservadas }\end{array}$ & 5,9 & $\begin{array}{l}\text { Qualidade do café } \\
\text { da manhã }\end{array}$ & 5,2 \\
\hline Conduta dos funcionários & 5,2 & $\begin{array}{l}\text { Variedade do café } \\
\text { da manhã }\end{array}$ & 2,2 \\
\hline Soluções a problemas & 4,0 & Qualidade do restaurante & 2,2 \\
\hline $\begin{array}{c}\text { Tempo de } \\
\text { check-in / check-out }\end{array}$ & 3,3 & Serviço de copa & 1,8 \\
\hline $\begin{array}{l}\text { Aparência dos } \\
\text { funcionários }\end{array}$ & 2,0 & & \\
\hline
\end{tabular}

Fonte: elaborada pelos autores.

Tabela 7. Atributos mais importantes $(75,4 \%$ da qualidade percebida).

\begin{tabular}{|c|c|c|c|}
\hline Ranking & Atributo & $\%$ & $\%$ Acumulado \\
\hline 1 & Limpeza do quarto & 9,2 & 9,2 \\
\hline 2 & Conforto do quarto & 7,0 & 16,2 \\
\hline 3 & $\begin{array}{l}\text { Exatidão das acomodações } \\
\text { reservadas }\end{array}$ & 5,9 & 22,1 \\
\hline 4 & Aparência interna & 5,6 & 27,7 \\
\hline 5 & Limpeza do hotel & 5,6 & 33,3 \\
\hline 6 & Conduta dos funcionários & 5,2 & 38,5 \\
\hline 7 & Qualidade do café da manhã & 5,2 & 43,7 \\
\hline 8 & $\begin{array}{c}\text { Disponibilidade de facilidades } \\
\text { (TV, TV a cabo, } \\
\text { rede wireless, rádio) }\end{array}$ & 4,5 & 48,2 \\
\hline 9 & $\begin{array}{l}\text { Disponibilidade de áreas de } \\
\text { lazer (piscina, churrasqueira...) }\end{array}$ & 4,4 & 52,7 \\
\hline 10 & Localização do hotel & 4,1 & 56,8 \\
\hline 11 & Soluções a problemas & 4,0 & 60,7 \\
\hline 12 & Segurança do hotel & 3,9 & 64,6 \\
\hline 13 & Ambiente silencioso & 3,8 & 68,5 \\
\hline 14 & $\begin{array}{c}\text { Disponibilidade de facilidades } \\
\text { esportivas (academia, quadra } \\
\text { de tênis...) }\end{array}$ & 3,6 & 72,1 \\
\hline 15 & Tempo de check-in / check-out & 3,3 & 75,4 \\
\hline
\end{tabular}

Fonte: elaborada pelos autores. 
Ramos e Amorim (2005) aponta a qualidade do restaurante como um dos principais atributos de qualidade percebida em hotéis. Neste estudo, a qualidade do restaurante não se destacou entre os atributos mais importantes na percepção de qualidade dos clientes, porém a qualidade do café da manhã obteve a sétima posição em importância. Provavelmente isso ocorra porque a maioria dos clientes utiliza apenas o café da manhã oferecido pelo hotel. A pesquisa de Akan (1995) apontou que a aparência física dos funcionários constitui um atributo de grande importância na qualidade percebida por clientes na Turquia. No entanto, no presente trabalho, a aparência dos funcionários foi um atributo de menor impacto, como mostram os resultados da Tabela 6 . Por fim, a disponibilidade de estacionamento, indicada como atributo importante da qualidade percebida nas pesquisas de Cadotte e Turgeon (1988), não se destacou entre os atributos de maior impacto neste trabalho.

\section{Conclusões}

0 presente artigo teve como objetivos a construção de um modelo de satisfação dos clientes para o serviço de hotelaria, através do estudo da relação entre eles e a investigação dos atributos que afetam a qualidade percebida dos clientes para o serviço em estudo.

Para alcançar todos os objetivos do trabalho, foram realizadas duas pesquisas envolvendo clientes de serviços de hotelaria. Na primeira fase, foi realizada a identificação das relações existentes entre os determinantes da satisfação de clientes. Para tanto, foi feito um levantamento através de um questionário, em que foram entrevistados 50 clientes do serviço em estudo. A partir desses dados foi possível construir o modelo de satisfação para serviços de hotelaria, adotando a abordagem proposta por Tinoco e Ribeiro (2007). A segunda pesquisa descritiva consistiu em uma investigação sobre a importância dos atributos da qualidade percebida pelos clientes de serviços de hotelaria. Ela foi realizada utilizando outro questionário, também aplicado a 50 clientes. Após o tratamento estatístico dos dados, foi possível hierarquizar os atributos e identificar aqueles de maior influência sobre a qualidade percebida pelo cliente.

Os principais resultados do estudo foram o modelo de associação, definindo o relacionamento entre os determinantes da satisfação de clientes de serviços de hotelaria e a hierarquização dos atributos que afetam a qualidade percebida dos clientes do mesmo serviço.
Da análise do modelo de satisfação destacam-se: (i) o forte relacionamento entre os elementos do triângulo formado pela satisfação do cliente; desconfirmação das expectativas e qualidade percebida; e (ii) o forte encadeamento causal entre os determinantes imagem corporativa, expectativas, confirmação / desconfirmação das expectativas e satisfação, sofrendo esse último bloco influência direta da qualidade percebida.

Os principais atributos da qualidade encontrados na pesquisa foram: limpeza do quarto, conforto do quarto, exatidão das acomodações reservadas, aparência interna, limpeza do hotel, conduta dos funcionários, qualidade do café da manhã, disponibilidade de facilidades (TV, TV a cabo...), disponibilidade de áreas de lazer, localização do hotel, soluções a problemas, segurança do hotel, ambiente silencioso, disponibilidade de facilidades esportivas, tempo de check-in / check-out.

Uma das limitações deste trabalho é o uso de uma amostra não estratificada. A sugestão é que em trabalhos futuros sejam realizados estudos explorando a influência do tipo de hotel (pousada, resorts, executivos), motivo da viagem (turismo, trabalho) e idade (jovens, casais com filhos, terceira idade). 0 modelo apresentado neste trabalho caracteriza um quadro geral estabelecendo uma referência para o setor. Estudos de segmentos específicos ajudariam a aprofundar o conhecimento dos serviços de hotelaria.

\section{Referências}

AKAN, P. Dimensions of service quality: a study in lstanbul. Managing Service Quality, v. 5, n. 6, p. 39-43, 1995.

ANDREASSEN, T.; LINDESTAD, B. Customer loyalty and complex services. International Journal of Service Industry Management, v. 9, n. 1, p. 7-23, 1998.

ANJOS, S. et al. Qualidade percebida dos serviços hoteleiros de Balneário Camboriú: uma proposta de análise. In: ENCONTRO NACIONAL DE ENGENHARIA DE PRODUCÃO - ENEGEP, 25. 2005, Porto Alegre. Anais...

ASSOCIAÇÃO BRASILEIRA DA INDÚSTRIA DE HOTÉIS - ABIH. Disponivel em: <http:// www.abih.com.br/>. Acesso em: 26 mar. 2008.

BIGNÉ, J. E.; MATTILA, A. S.; ANDREU, L. The impact of experiential consumption cognitions and emotions on behavioral intentions. Journal of Services Marketing, v. 22, n. 4, p. 303-315, 2008.

CADOTTE, E. R.; TURGEON, N. Key factors in guest satisfaction. Cornell Hotel and Restaurant Administration Quarterly, p. 44-51, 1988.

CARO, L. M.; GARCÍA, J. A. M. Cognitive-affective model of consumer satisfaction. An exploratory study within the framework of a sporting event. Journal of Business Research, v. 60, p. 108-114, 2007.

CHAN, E. S. W.; WONG, S. C. K. Hotel selection: when price is not the issue. Journal of Vacation Marketing, v. 12, n. 2, p. 142-159, 2006.

$\mathrm{CHOl}$, K. S. et al. The relationships among quality, value, satisfaction and behavioral intention in health care provider 
choice: A South Korean study. Journal of Business Research, v. 57, p. 913-921, 2004.

CHURCHILL, G. A.; SURPRENANT, C. An investigation into the determinants of customer satisfaction. Journal of Marketing Research, v. 19, p. 491-504, 1982.

FARIAS, S.; SANTOS, R. Atributos de satisfação nos serviços de hotelaria: uma perspectiva no segmento de terceira idade. In: ENCONTRO DA ASSOCIAÇÃO NACIONAL DE PÓS-GRADUAÇÕES EM ADMINISTRAÇÃO - ENANPAD, 1998, Foz do lguaçu. Anais...

FITZSIMMONS, J. A.; FITZSIMMONS, M. J. Administração de Serviços: operações, estratégia e tecnologia da informação. 4 ed. Porto Alegre: Bookman, 2005. 564 p.

GIANESI, 1. G. N.; CORRÊA, H. L. Administração Estratégica de Serviços: operações para a satisfação de clientes. São Paulo: Atlas, 2006. 233 p.

GONZÁLEZ, M. O. A.; RAMOS, R. E. B.; AMORIM, C. G. Gestão da satisfação e da fidelidade do cliente na hotelaria: um estudo dos fatores que influenciam a satisfação e a fidelidade do turista internacional no Brasil. In: ENCONTRO NACIONAL DE ENGENHARIA DE PRODUÇÃO - ENEGEP, 25., 2005, Porto Alegre. Anais...

GOSLING, M.; GONÇALVES, C. A. Modelagem por Equações Estruturais: conceitos e aplicações. Revista FACES - Revista de Administração, 2003.

GRÖNROOS, C. Service Management and Marketing: Customer Management in Service Competition. 3 ed. England: John Wiley \& Sons, 2007. 483 p.

HAIR, JR. et al. Multivariate data analysis. 5 ed. New Jersey: Prentice Hall, 1998. 666 p.

INSTITUTO BRASILEIRO DE GEOGRAFIA E ESTATÍSTICA - IBGE. Sistemas de Contas Nacionais 2002-2006. Rio de Janeiro, 2008. Disponivel em: <http://www.ibge.gov.br/home/estatistica/ economia/contasnacionais/referencia2000/2002_2006/ sicona2002_2006.pdf>. Acesso em: 19 dez. 2008.

JIANG, Y.; WANG, C. L. The impact of affect on service quality and satisfaction: the moderation of service contexts. Journal of Services Marketing, v. 20, n. 4, p. 211-218, 2006.

JOHNSON, M.; NADER, G.; FORNELL, C. Expectations, perceived performance, and customer satisfaction for a complex service: the case of bank loans. Journal of Economic Psychology, v. 17, p. 163-184, 1996.

KOTLER, P.; KELLER, K. L. Administração de Marketing. 12. ed. São Paulo: Pearson Prentice Hall, 2006. 750 p.

LAl, F. et al. How quality, value, image, and satisfaction create loyalty at a Chinese telecom. Journal of Business Research, v. 62, p. 980-986, 2009.

LOVELOCK, C.; WRIGHT, L. Serviços: marketing e gestão. São Paulo: Saraiva, 2001. 416 p.
MARTIN, D. et al. The role of emotion in explaining consumer satisfaction and future behavioural intention. Journal of Services Marketing, v. 22, n. 3, p. 224-236, 2008.

MORGAN, N. A.; REGO, L. L. The Value of different customer satisfaction and loyalty metrics in predicting business performance. Marketing Science, v. 25, n. 5, p. 426-439, 2006.

OLIVER, R. L. A cognitive model of the antecedents and consequences of satisfaction decisions. Journal of Marketing Research, v. 17, p. 460/469, 1980.

OLIVER, R. L. Cognitive, affective, and attribute bases of satisfaction response. Journal of Consumer Research, vol. 20, p. 418/430, 1993.

PARASURAMAN, A.; ZEITHAML, V. A.; BERRY, L. L. A conceptual model of service quality and its implications for future research. Journal of Marketing, v. 49, n. 4, p. 41-50, 1985.

PIZAM, A.; ELLIS, T. Customer satisfaction and its measurement in hospitality enterprises. International Journal of Contemporary Hospitality Management, v. 11, n. 7, p. 326-339, 1999.

SHETH, J. N.; MITTAL, B.; NEWMAN, B. 1. Comportamento do Cliente: indo além do comportamento do consumidor. São Paulo: Atlas, 2001. 795 p.

TINOCO, M. A. Proposta de modelos de satisfação dos consumidores de serviços. 2006. Dissertação (Mestrado em Engenharia de Produção) - Universidade Federal do Rio Grande do Sul, 2006.

TINOCO, M. A.; RIBEIRO, J. L. Uma nova abordagem para a modelagem das relações entre os determinantes da satisfação dos clientes de serviços. Revista Produção, v. 17, n. 3, 2007.

Van RYZIN, G. G. Testing the Expectancy Disconfirmation Model of Citizen Satisfaction with Local Government. Journal of Public Administration Research and Theory, 2005.

VLACHOS, P. A.; VRECHOPOULOS, A. P. Determinants of behavioral intentions in the mobile internet services market. Journal of Services Marketing, v. 22, n. 4, p. 280-291, 2008.

WHITTAKER, G.; LEDDEN, L.; KALAFATIS, S. P. A re-examination of the relationship between value, satisfaction and intention in business services. Journal of Services Marketing, v. 21, n. 5, p. 345-357, 2007.

\section{Agradecimentos}

Os autores agradecem à CAPES (Coordenação de Aperfeiçoamento de Pessoal de Nível Superior) e ao CNPq (Conselho Nacional de Pesquisa e Desenvolvimento) pela concessão de bolsas de pesquisa que auxiliaram na elaboração deste trabalho.

\title{
Satisfaction determinants and quality attributes in hotel services
}

\begin{abstract}
This paper addresses the identification of quality attributes and the construction of a model to describe the relationship among satisfaction determinants for hotel services. The research was conducted surveying 100 clients of the service under focus. The principal contribution of this study concerns the proposal of a model which details the strength of the relationship among satisfaction determinants and ranks the attributes that influence customer-perceived quality in hotel services. Results can be used by hotel managers to achieve customer satisfaction and improve the company's income. This research complements other studies on quality and customer satisfaction in hotel services.
\end{abstract}

Keywords

Customer satisfaction. Quality attributes. Hotel services. 
Apêndice 1. Questionário de atributos.

\begin{tabular}{|c|c|c|}
\hline \multicolumn{2}{|c|}{ Tipo de serviço: Hotel } & úmero de questionário: \\
\hline \multicolumn{3}{|c|}{$\begin{array}{l}\text { Com a finalidade de identificar a importância dos principais atributos que afetam a qualidade percebida pelos clientes desse tipo de serviço, solicita-se responder } \\
\text { o questionário a seguir, ordenando os atributos de cada grupo, indicando " } 1 \text { " para o mais importante e ordens crescentes }(2,3,4 . . .) \text { para os demais. }\end{array}$} \\
\hline $\begin{array}{l}\text { Aspectos gerais externos } \\
\text { () Acesso } \\
\text { () Ambiente externo do hotel } \\
\text { () Aparência externa do hotel } \\
\text { () Disponibilidade de estacionamento } \\
\text { () Localização do hotel }\end{array}$ & $\begin{array}{l}\text { Atendimento } \\
\text { () Aparência dos funcionários } \\
\text { () Conduta dos funcionários } \\
\text { () Exatidão das acomodações reservadas } \\
\text { () Tempo de check-in / check-out } \\
\text { () Soluções a problemas }\end{array}$ & $\begin{array}{l}\text { Quarto } \\
\text { () Conforto do quarto } \\
\text { () Disponibilidade de facilidades } \\
\text { (TV, TV a cabo, rede wireless, rádio) } \\
\text { () Espaço do quarto } \\
\text { () Limpeza do quarto } \\
\text { () Ambiente silencioso }\end{array}$ \\
\hline $\begin{array}{l}\text { Aspectos gerais internos } \\
\text { () Disponibilidade de lavanderia } \\
\text { () Formas de pagamento } \\
\text { () Limpeza do hotel } \\
\text { () Segurança do hotel }\end{array}$ & $\begin{array}{l}\text { Infraestrutura } \\
\text { () Aparência interna } \\
\text { () Espaço do hall } \\
\text { () Disponibilidade de facilidades esportivas } \\
\text { (academia, quadra de tênis...) } \\
\text { () Disponibilidade de áreas de lazer } \\
\text { (piscina, churrasqueira....) }\end{array}$ & $\begin{array}{l}\text { Serviços de alimentação } \\
\text { () Qualidade do café da manhã } \\
\text { () Qualidade do restaurante } \\
\text { () Serviço de copa } \\
\text { () Variedade do café da manhã }\end{array}$ \\
\hline $\begin{array}{l}\text { Também se pede que se ordene a impc } \\
\text { () Aspectos gerais externos } \\
\text { () Aspectos gerais internos } \\
\text { () Atendimento } \\
\text { () Infraestrutura } \\
\text { () Quarto } \\
\text { () Serviços de alimentação }\end{array}$ & grupos: & \\
\hline
\end{tabular}

Anexo 1. Questionário de determinantes.

\begin{tabular}{|c|c|c|}
\hline Tipo de serviço: Hotel & \multicolumn{2}{|c|}{ Número de questionário: } \\
\hline \multicolumn{3}{|c|}{$\begin{array}{l}\text { Com a finalidade de identificar os determinantes principais que afetam a satisfação dos clientes desse tipo de serviço, solicita-se responder o questionário a segui } \\
\text { selecionando uma, várias ou nenhuma das alternativas: }\end{array}$} \\
\hline $\begin{array}{l}\text { 1. A Imagem corporativa da empresa de serviço } \\
\text { depende principalmente de: } \\
\text { a. Desejos pessoais } \\
\text { b. Expectativas } \\
\text { c. Emoções vivenciadas no momento } \\
\text { d. Qualidade percebida } \\
\text { e. Preço do serviço } \\
\text { f. Valor do serviço } \\
\text { g. Desconfirmação de expectativas } \\
\text { h. Satisfação gerada pelo serviço }\end{array}$ & $\begin{array}{l}\text { 4. As Emoções vivenciadas no momento dependem } \\
\text { principalmente de: } \\
\text { a. Imagem corporativa } \\
\text { b. Desejos pessoais } \\
\text { c. Expectativas } \\
\text { d. Qualidade percebida } \\
\text { e. Preço do serviço } \\
\text { f. Valor do serviço } \\
\text { g. Desconfirmação de expectativas } \\
\text { h. Satisfação gerada pelo serviço } \\
\end{array}$ & $\begin{array}{l}\text { 7. O Valor do serviço depende principalmente de: } \\
\text { a. Imagem corporativa } \\
\text { b. Desejos pessoais } \\
\text { c. Expectativas } \\
\text { d. Emoções vivenciadas no momento } \\
\text { e. Qualidade percebida } \\
\text { f. Preço do serviço } \\
\text { g. Desconfirmação de expectativas } \\
\text { h. Satisfação gerada pelo serviço }\end{array}$ \\
\hline $\begin{array}{l}\text { 2. Os Desejos pessoais dos clientes dependem } \\
\text { principalmente de: } \\
\text { a. Imagem corporativa } \\
\text { b. Expectativas } \\
\text { c. Emoções vivenciadas no momento } \\
\text { d. Qualidade percebida } \\
\text { e. Preço do serviço } \\
\text { f. Valor do serviço } \\
\text { g. Desconfirmação de expectativas } \\
\text { h. Satisfação gerada pelo serviço }\end{array}$ & $\begin{array}{l}\text { 5. A Qualidade percebida do cliente em relação ao } \\
\text { serviço depende principalmente de: } \\
\text { a. Imagem corporativa } \\
\text { b. Desejos pessoais } \\
\text { c. Expectativas } \\
\text { d. Emoções vivenciadas no momento } \\
\text { e. Preço do serviço } \\
\text { f. Valor do serviço } \\
\text { g. Desconfirmação de expectativas } \\
\text { h. Satisfação gerada pelo serviço }\end{array}$ & $\begin{array}{l}\text { 8. A Desconfirmação de expectativas depende } \\
\text { principalmente de: } \\
\text { a. Imagem corporativa } \\
\text { b. Desejos pessoais } \\
\text { c. Expectativas } \\
\text { d. Emoções vivenciadas no momento } \\
\text { e. Qualidade percebida } \\
\text { f. Preço do serviço } \\
\text { g. Valor do serviço } \\
\text { h. Satisfação gerada pelo serviço }\end{array}$ \\
\hline $\begin{array}{l}\text { 3. As Expectativas dos clientes dependem } \\
\text { principalmente de: } \\
\text { a. Imagem corporativa } \\
\text { b. Desejos pessoais } \\
\text { c. Emoções vivenciadas no momento } \\
\text { d. Qualidade percebida } \\
\text { e. Preço do serviço } \\
\text { f. Valor do serviço } \\
\text { g. Desconfirmação de expectativas } \\
\text { h. Satisfação gerada pelo serviço }\end{array}$ & $\begin{array}{l}\text { 6. O Preço do serviço depende principalmente de: } \\
\text { a. Imagem corporativa } \\
\text { b. Desejos pessoais } \\
\text { c. Expectativas } \\
\text { d. Emoções vivenciadas no momento } \\
\text { e. Qualidade percebida } \\
\text { f. Valor do serviço } \\
\text { g. Desconfirmação de expectativas } \\
\text { h. Satisfação gerada pelo serviço }\end{array}$ & $\begin{array}{l}\text { 9. A Satisfação gerada pelo serviço depende } \\
\text { principalmente de: } \\
\text { a. Imagem corporativa } \\
\text { b. Desejos pessoais } \\
\text { c. Expectativas } \\
\text { d. Emoções vivenciadas no momento } \\
\text { e. Qualidade percebida } \\
\text { f. Preço do serviço } \\
\text { g. Valor do serviço } \\
\text { h. Desconfirmação de expectativas }\end{array}$ \\
\hline
\end{tabular}

Anexo 2. Definições.

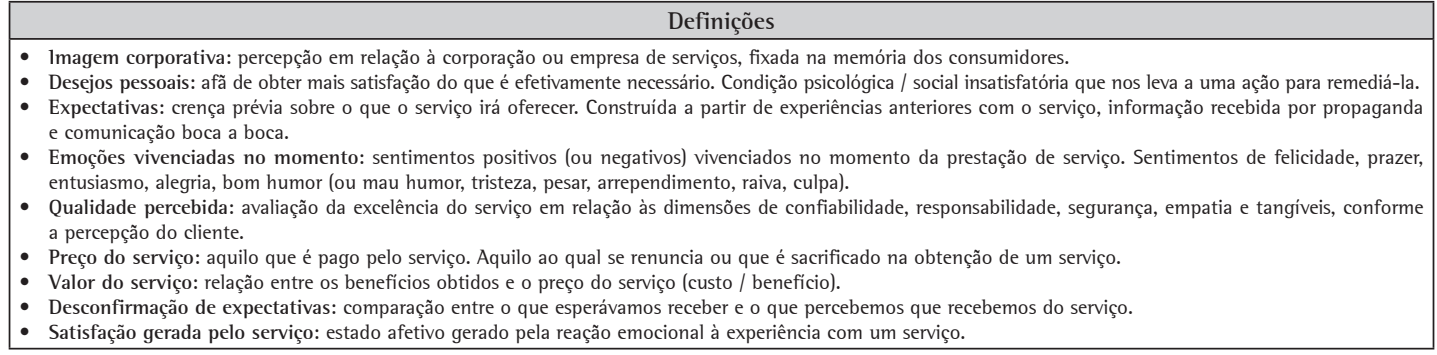

